\title{
Pseudoxantoma Elástico
}

\author{
Aida García Péreza , Pascual Peña Ibáñez ${ }^{a}$, \\ Pilar Sánchez Ortiz ${ }^{\mathrm{b}}$
}

\begin{abstract}
${ }^{a}$ Residente de Medicina Familiar y Comunitaria, Centro de Salud Hellín II (Albacete).

${ }^{\mathrm{b}}$ Especialista en Medicina Familiar y Comunitaria, Centro de Salud Hellín II (Albacete).

Correspondencia: Pilar Sánchez Ortiz, Centro de Salud Hellín II, C/ Las Turbas de Cuenca s/n, 02400-Hellín (Albacete, España). Telf.: 967542406, e-mail: pilarsortiz@hotmail.com.
\end{abstract}

Recibido el 26 de febrero de 2010.

Aceptado para su publicación el 21 de abril de 2010.

\section{RESUMEN}

El pseudoxantoma elástico es una enfermedad hereditaria del tejido conectivo caracterizada por calcificación y fragmentación progresivas de las fibras elásticas en distintos tejidos. La prevalencia de la enfermedad se estima en 1 de cada 25,000 a 100,000 habitantes y es dos veces más frecuente en mujeres. Su diagnostico precoz ayuda a prevenir las futuras complicaciones que estos pacientes pueden desarrollar.

Palabras clave. Pseudoxantoma Elástico.

\section{ABSTRACT}

\section{Pseudoxanthoma elasticum}

Pseudoxanthoma elasticum is a genetic disorder of the connective tissue characterised by progressive calcification and fragmentation of the elastic fibres in different body tissues. It has an estimated prevalence of 1 case in 25,000 to 100,000 population and is twice as common in women. Early diagnosis helps to prevent further complications these patients could develop.

Key words. Pseudoxanthoma Elasticum.

\section{INTRODUCCIÓN}

El pseudoxantoma elástico es una enfermedad hereditaria del tejido conectivo que se caracteriza por calcificación y fragmentación progresivas de las fibras elásticas en distintos tejidos, que incluyen piel, ojos y sistema cardiovascular. La causa más frecuente de morbilidad es la disminución de agudeza visual por hemorragia macular.

Presenta dos tipos de trasmisión hereditaria: autosómica recesiva, la más frecuente, y autosómica dominante, más infrecuente. Estudios genéticos recientes han localizado el locus del pseudoxantoma elástico en el brazo corto del cromosoma 16p 13:1. El defecto radicaría en el gen ABCC6 (MRP6) y por tal causa se especula que el pseudoxantoma elástico no afectaría solamente las fibras elásticas sino que sería una enfermedad metabólica que afecta el ensamble del tejido conectivo.

La prevalencia de la enfermedad se estima en 1 de cada 25.000 a 100.000 habitantes y es dos veces más frecuente en mujeres. Es una entidad de la que habitualmente no se sospecha, por ello, el interés en presentar este caso, ya que el diagnostico precoz ayuda a prevenir las futuras complicaciones que estos pacientes pueden desarrollar.

\section{OBSERVACIONES CLÍNICAS}

Varón de 24 años que acude a consulta de Atención Primaria por lesiones cutáneas a nivel cervical e inguinal de 4 años de evolución. No presenta antecedentes personales ni familiares de interés. En la exploración física presen- 
ta lesiones máculo-papulosas de coloración amarillenta en cuello e ingles, que simulan el aspecto de "piel de gallina" (figura 1). A la palpación estas lesiones son laxas y blandas. El resto de la exploración física no presenta alteraciones de interés.

Continuando el estudio de las lesiones del paciente se realiza analítica general que pone de manifiesto hipertrigliceridemia. Posteriormente se deriva al paciente a la consulta de Dermatología, donde se realizan varias biopsias de las lesiones cutáneas. El informe anatomopatológico de las biopsias es: presencia de abundantes fibras elásticas anormales, basófilas, cortas, engrosadas y calcificadas en dermis reticular.

\section{COMENTARIOS}

El pseudoxantoma elástico es una enfermedad sistémica hereditaria que se caracteriza por una elastorrexis generalizada de las fibras elásticas con posterior calcificación de las mismas, y consecuentes manifestaciones sistémicas.

Las manifestaciones cutáneas constituyen la primera manifestación del pseudoxantoma elástico. Pueden observarse desde la infancia o la adolescencia, en forma de pápulas amarillentas con tendencia a la confluencia y la formación de áreas de piel con aspecto laxo, hiperelástico y redundante conocidas como "piel de gallina", "de naranja" o "en empedrado". Las lesiones se localizan inicialmente en el cuello, extendiéndose posteriormente en dirección caudal para afectar los grandes pliegues y la región periumbilical. Pocas veces se observan lesiones en las mucosas.

Las manifestación ocular más precoz es una alteración del pigmento retiniano en "piel de naranja", pero la más característica (aunque no patognomónica) es la presencia de las denominadas "estrías angioides" que corresponden a desgarros de la membrana de Bruch y pueden dar lugar a hemorragias y cicatrices retinianas.

Las manifestaciones sistémicas del trastorno del tejido conectivo en las formas más graves de la enfermedad pueden dar lugar a claudicación intermitente, aneurismas arteriales, cardiopatía coronaria, accidentes cerebrovasculares, equimosis, hemartrosis y hemorragias uterinas y gastrointestinales, que plantean un grave riesgo para la vida del paciente.

\section{BIBLIOGRAFÍA}

- Puig Sanz L. Enfermedades Hereditarias con Importante Componente Dermatológico. En: Ferrándiz C, editor. Dermatología Clínica. Sa ed. Madrid: Harcourt; 2001. p. 259-260.

- Wolff K, Goldsmith LA. Dermatología en Medicina General. $7^{\mathrm{a}}$ ed, vol. 4. Buenos Aires: Editorial Panamericana; 2009. p. 1304-1308.

- Barzallo, M. Pseudoxantoma elástico. Revista Científica Sociedad Ecuatoriana de Dermatología 2007; 4(2). Disponible en: http://www.medicosecuador.com/.../pseudoxantoma elastico.htm

- Ocampo E, Verdi M, Balsells L, Zusaeta M. Descubriendo El Pseudoxantoma Elástico. Rev Argent Dermatol. 2006; 87: 6-14.

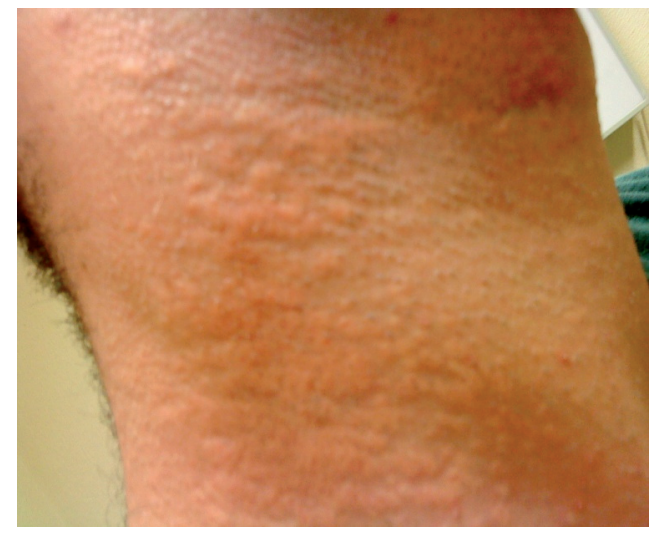

Figura 1. Placas maculo-papulosas amarillentas "piel de naranja" en cuello. 